\title{
Assessment of the Research Capacity of the Centers for Health Development, Philippine Department of Health
}

\author{
Maria Carmen C. Tolabing and Maylin C. Palatino \\ Department of Epidemiology and Biostatistics, College of Public Health, University of the Philippines Manila
}

\begin{abstract}
Background. In 2012, the Philippine Department of Health (DOH) established the Health Systems Research Management (HSRM). One of the HSRM components is increasing the research capacity of the Centers for Health Development (CHD) which is the regional office of the $\mathrm{DOH}$.

Objective. To determine the research capacity of CHDs and to describe research input, research process, and research output.

Methods. A descriptive cross-sectional study design was employed. The data were collected using self-administered questionnaire with the Regional Director as the CHD respondent. The research capacity level was determined using rating scale measurement. Based on the ratings, each CHD was assigned a score with the corresponding capacity level: excellent (85-100\%); good (70-84\%); fair (51-69\%); poor (<50\%).
\end{abstract}

Results. Fourteen (82\%) of the 17 CHDs participated in the study. The institutional capacity level of the CHDs was poor in the areas of research management (43.0\%) and in structure/ organization/ monitoring/ evaluation (30.0\%), while it was fair in the area of resource mobilization (54.5\%). Research input, research process, and research output were found to be lacking.

Conclusion. The capacity level of the CHDs in the various aspects of institutional research ranged from poor to fair. Specific areas under research input, research process, and research output that need improvement were identified which can be used as benchmark for capacity-building activities and as information-base against which the effectiveness of these activities in the CHDs can be evaluated.

Key Words: center for health development, institutional capacity, research assessment, research capacity

\section{INTRODUCTION}

In 2012, the Philippine Department of Health (DOH) established the Health Systems Research Management (HSRM) as a strategy to address the need for evidence-based health policies, plans, and programs. Specifically, HSRM aimed to achieve the following: 1) to generate more health researches to support the implementation of Universal Health Care; 2) to increase capacity for research, knowledge production, use of researches for policy and programs, research management and financing; 3) to collaborate and

Corresponding author: Maria Carmen C. Tolabing, MPH, DrPH Department of Epidemiology and Biostatistics

College of Public Health

University of the Philippines Manila

625 Pedro Gil Street, Ermita, Manila 1000 Philippines

Telephone: +6325247118

Email: ctolabing@gmail.com partner with research institutions to strengthen the health policy research system management in the $\mathrm{DOH}$; and 4) to mobilize/manage resources for research projects and activities effectively. ${ }^{1}$

The establishment of HSRM is in line with the commitment of $\mathrm{DOH}$ to provide a responsive health system, 
financial risk protection, and better health outcomes to Filipinos. ${ }^{1}$ One of the components of HSRM is a 3-year program to develop the research capability of $\mathrm{DOH}$ regional units, entitled, "Capability building program for the Center for Health Development offices and regional hospitals". ${ }^{2}$ The first year of the development program consisted of a baseline assessment of the research capacity of the Center for Health Development (CHD) offices and regional hospitals (RH) and research skills training of CHD staff.

The Philippine National Health Research System defines capacity building as "the upgrading of different human and institutional resources to improve conduct, analysis, and use of health research". ${ }^{3}$ This definition was adopted by the Department of Science and Technology - Philippine Council for Health Research and Development (DOST-PCHRD). The required inputs to promote and ensure research capacity include human resources, infrastructure, facilities, equipment, databases, materials, and financial or monetary resources, and incentives, as well as the support system such as the administrative or management support that assure proper functioning and success of the research activity. ${ }^{3}$

Two areas of development are, thus, required in building the research capacity of an institution. First is development of human abilities and competencies to do research. Second is the upgrading of institutional structures and systems to improve the conduct, analysis, communication, and use of research. The mix of knowledge, skills, structures, and systems required for research productivity is expected to lead to the desired increase in research capacity of an institution to do research and to support research.

In this paper, the results only describe baseline research on institutional research capacity of the CHDs. The CHD is the regional office of the Department of Health which is responsible for its field operations in each region of the country. Among the functions of the DOH, as contained in Executive Order 119 signed by the President of the Philippines in 1987, is to "undertake health and medical research and conduct training in support of its priorities, programs, and activities". ${ }^{4}$

The objective of this research was twofold: 1) to describe research input, process, and output in the CHD; and 2) to determine the capacity level of the CHD in terms of research management, resource mobilization/structure/ organization/ monitoring and evaluation processes. The results can serve several purposes, among them, as benchmark for future project activities on research in the CHDs and as basis for determining priority areas which need more focus in planning the capacity-building program of the Department of Health.

\section{METHODS}

\section{Research design and setting}

This research employed a descriptive cross-sectional study to determine the institutional research capacity of the regional offices of DOH - Center for Health Development Office in the administrative regions. There are 17 administrative regions and one autonomous region in the country which are distributed across the three main island groupings: Luzon (8 regions); Visayas (4 regions); and Mindanao (5 administrative regions and 1 autonomous region). The crosssectional data were collected during the period from October to November 2013. The framework utilized in this baseline study is the input-process-output framework developed by PCHRD contained in the document entitled, "Assessment tools of research capacity building for researchers, research institutions and regional research consortia". ${ }^{3}$ This framework was utilized to assess the research capacity of CHDs for two reasons. First, the framework was very relevant to our research as it identified research components which were of interest in the study: inputs, process, and outputs. Second, the framework was based on the 2009 research assessment framework developed by the Philippine National Health Research System (PNHRS). As such, it was deemed appropriate to meet our local context.

\section{Participants}

All the 17 CHD-regional offices in the administrative regions were invited to take part in the institutional research capacity assessment with the Regional Director as the CHD respondent. The invitation letters were sent to all the $\mathrm{CHD}$ Regional Directors through email and courier. Since the research aimed to look at research capacity of the $\mathrm{CHD}$ as an institution, the respondent was told that s/he may discuss the questionnaire with the other people in the organization and that they can work together on the answers.

\section{Data collection}

Data were collected from each CHD using anonymous self-administered questionnaire. The questionnaire consisted of 6 sections: inputs, outputs, process, research management, resource mobilization, and structure/ organization/ monitoring/ evaluation (SOME). The first three sections consisted of open-ended and closed-ended questions which we formulated based on the concepts presented in the PCHRD research framework. These questions aimed to describe the $\mathrm{CHDs}$ research input, process, and outputs. The last three sections consisted of a rating scale measurement adapted from the Research Institution Capacity Assessment Tool (RICAT) developed by PCHRD to assess research capacity level. The research capacity questionnaire used in our study was a modified version of the RICAT. ${ }^{3}$ Only three of the 6 research areas covered in the RICAT were utilized (research management, resource mobilization, and SOME). The research capacity level of the CHDs in these three areas was measured using 13 indicators for research management, 5 for resource mobilization, and 7 for SOME which were adapted verbatim from RICAT for each area. Respondents were asked to choose from among three rating options (item is not met, item is partially met, and item is satisfactorily met). 
The questionnaire was pretested only through expert evaluation. Field testing of the questionnaire was not completed due to time constraints. The evaluation for both form and content validity was carried out by the Research Division of the Health Policy Development and Planning Bureau of the DOH.

\section{Data analysis}

The unit of analysis in this study is the CHD as an institution. Data on research inputs and outputs were summarized quantitatively using means/medians for quantitative variables and proportions for qualitative variables. The ratings (satisfactorily met, met partially, and not met) on the indicators for capacity level in the areas of research management, resource mobilization, and SOME were analyzed quantitatively. There are four levels of research capacity based on a RICAT scoring system: Level IIIEXCELLENT (score = 85-100\%); Level II - GOOD (score = 70-84\%); Level I - FAIR (score= 51-69\%); and Level 0 - POOR (score of <50\%). ${ }^{3}$ Median rating was computed to describe the typical rating of the CHDs on the various indicators of research capacity and mean was the summary measure used to determine the typical capacity level of the CHDs for each of the three areas assessed. The scoring system is as follows:

Scoring system for capacity level (RICAT) ${ }^{3}$

Scores for each indicator

0 - Provision or item is not met or not observed.

1 - Provision or item is met partially and amendments, revisions, or additions are required.

2 - Provision or item is met satisfactorily; no modifications necessary.

Scoring procedure

Total score for each research area assessed divided by the perfect score for that area and multiplied by 100 to get the percentage score.

\section{Operational definition of terms}

1. Research capability - human abilities and competencies to conduct health research ${ }^{3}$

2. Research capacity - human and institutional resources to improve conduct, analysis, and use of health research ${ }^{3}$

3. Research input - resources utilized to achieve the desired outputs and includes human/ material/ monetary resources, as well as systems to support the proper functioning of research activities ${ }^{3}$

4. Research output - knowledge and products produced from research activities ${ }^{3}$

5. Research process - procedures, mechanisms, policies, and standards that are in place and are being monitored $^{3}$

\section{Ethical considerations}

The research was carried out with the following ethical considerations: a) the identity of the study participants was kept anonymous. The questionnaire did not contain information that could identify the respondent nor the participating institution; b) access to the hard copy of the accomplished questionnaire as well as the questionnaire file serving as repository of responses was limited to the research team directly involved in data processing and analysis; and c) research results were reported as aggregate data.

\section{Validation and dissemination of results}

A forum was held on 1 April 2014 for validation and dissemination of research results. The forum, entitled "Result of the CHD Research Capacity Assessment", was attended by 21 (47\%) of the invited officials of the CHD including 6 Assistant Regional Directors, 9 Research \& Development Coordinators, and 6 Planning Officers. Also present during the forum were key officials from the DOH Central Office and the Philippine Council for Health Research and Development: the head of DOH-Health Policy, Finance, and Research Development Cluster; the Chief of DOHHealth Policy Planning and Development Bureau-Research Division; and the Executive Director of the Philippine Council for Health Research and Development.

\section{RESULTS}

\section{Study participants}

Fourteen of the 17 CHDs (82\%) participated in this baseline research and was comprised of seven, three, and four regions located in Luzon, Visayas, and Mindanao, respectively.

\section{Research input}

Inputs. Ten of the CHDs had a research unit (71\%) but only seven (50\%) reported an existing technical review committee (TRC) of which only one (14\%) was active. Three of the CHDs (21\%) had an Ethics Review Committee (ERC), of which only 1 was active. In terms of resources, a large proportion (86\%) of the CHDs reported competence in research agenda setting, but not many are competent in the areas of designing research, technical writing, and evaluation of the technical/ethical quality of research proposals/ reports. The median annual budget for research for the 3-year period 2010-2012 was comparable (Php 600,000-645,000) (Table 1).

Process. Seven CHDs (50\%) had written policies related to research of which five were on funding for research proposals and two on commissioned researches. The proportion was also low in terms of availability of a written research development program plan (57\%) and in the conduct of institutional research agenda setting (36\%). Although all the CHDs have been members of the Regional Health Research and Development Consortium (RHRDC), not all were actively involved in activities of the consortium (Table 2).

Output. When asked about research outputs during the year preceding the study, five (36\%) of the CHDs replied that they were able to generate research proposals. The proposals 
were developed either in collaboration with other institutions or by parties commissioned by the CHD. The mean annual number of proposals produced, research projects funded, and projects completed was less than one, while the mean annual number of proposals implemented was one (Table 3).

\section{Research capacity level}

The research capacity level of the CHDs was measured using 25 indicators - 13 for research management, 5 for resource mobilization, and 7 for SOME. Only two of the 25 indicators were rated by the CHDs as "met satisfactorily" while the rest were either "partially met" (14 indicators) or "not met" (9 indicators) (Table 4). After processing the ratings to obtain the level of research capacity, we found, on the average, the following research capacity levels of the CHDs: FAIR for resource mobilization; POOR for research management; and POOR for SOME (Table 5).

Research management capacity. A total 13 indicators were used to measure research management capacity, of which only two were rated by the CHDs as "satisfactorily met", three as "not met" and the rest (8 indicators) as

Table 1. Research inputs in centers for health development, Philippines, November 2013 ( $n=14$ )

\begin{tabular}{|c|c|}
\hline Research Input & Number (\%) \\
\hline \multicolumn{2}{|l|}{ Structure/organization } \\
\hline Existence of research unit & $10(71)$ \\
\hline Existence of Research Technical Review Committee (TRC) & $7(50)$ \\
\hline Active TRC & $1(14)$ \\
\hline Existence of Research Ethics Review Committee (ERC) & $3(21)$ \\
\hline Active ERC & $1(33)$ \\
\hline \multicolumn{2}{|l|}{ Resources } \\
\hline \multicolumn{2}{|l|}{ Research staff competence } \\
\hline Setting research agenda using any agenda setting framework & $12(86)$ \\
\hline Designing or developing research proposal & $10(71)$ \\
\hline Evaluating the ethical quality of research proposal & $8(57)$ \\
\hline Technical writing/ writing research manuscript & $8(57)$ \\
\hline Evaluating the technical quality of research proposal & $7(50)$ \\
\hline Preparing a policy brief & $3(21)$ \\
\hline Statistical software for research & $11(79)$ \\
\hline Instructional materials/ modules on research methods & $7(50)$ \\
\hline Internet access to online research databases & $4(43)$ \\
\hline Access to scientific subscription & 0 \\
\hline Attendance in short term research training within the past 3 years & $11(79)$ \\
\hline \multirow[t]{3}{*}{ Budget for research (PhP), Median (Min-Max) } & $2010=600,000(100,000-1,000,000)$ \\
\hline & $2011=600,000(100,000-1,239,700)$ \\
\hline & $2012=645,390(150,000-8,000,000)$ \\
\hline \multirow[t]{3}{*}{$\%$ of research budget utilized exclusively for research } & $2010=41.1 \%$ \\
\hline & $2011=85.1 \%$ \\
\hline & $2012=60.4 \%$ \\
\hline
\end{tabular}

Table 2. Research processes in centers for health development, Philippines, November 2013 ( $n=14)$

\begin{tabular}{lc}
\multicolumn{1}{c}{ Research System } & Number (\%) \\
With written policies related to research & $7(50)$ \\
With written research development program plan & $8(57)$ \\
Undertakes institutional research agenda setting & $5(36)$ \\
Member of the Regional Health Research and & $14(100)$ \\
Development Consortium (RHRDC) & \\
Active participation in the following RHRDC activities: & \\
Research agenda setting of regional research priorities & $14(100)$ \\
Resource sharing/ funding counterpart & $13(93)$ \\
Research trainings as participant & $13(93)$ \\
Technical review of research proposals & $12(86)$ \\
Consortia meetings & $12(86)$ \\
Research trainings as resource person & $11(79)$ \\
Collaborative research & $9(64)$ \\
Ethical review of research proposals & $8(57)$ \\
Establishment and maintenance of electronic research & $6(43)$ \\
database &
\end{tabular}

Table 3. Research outputs of centers for health development, Philippines, November 2013

\begin{tabular}{lrc}
\multicolumn{1}{c}{ Research Outputs for the year 2012 } & $\begin{array}{c}\text { Number } \\
\text { (n) }\end{array}$ & $\begin{array}{c}\text { Mean } \\
\text { (min,max) }\end{array}$ \\
\hline Proposals developed by staff & 11 & $0.7(0,4)$ \\
Proposals developed by staff in collaboration & 9 & $0.7(0,4)$ \\
with other institutions & 9 & $0.4(0,3)$ \\
Commissioned proposal development & 12 & $1.0(0,7)$ \\
Research projects implemented & 12 & $0.7(0,4)$ \\
$\quad$ by CHD staff & 12 & $0.3(0,4)$ \\
$\quad$ commissioned & 12 & $0.4(0,4)$ \\
Research projects completed & 12 & $0.3(0,3)$ \\
$\quad$ by RHO staff & 12 & $0.1(0,1)$ \\
$\quad$ partly commissioned by CHD & & \\
Proposal funded by CHD & 10 & $0.6(0,2)$ \\
$\quad$ as a sole funding institution & 9 & $0.9(0,3)$ \\
$\quad$ as a co-funder & &
\end{tabular}


"partially met" (Table 4). One of the two indicators that was rated as "satisfactorily met" was on the selection and approval of researches by the committee following standardized procedures. The other was on the CHDs ability to direct and encourage researchers to focus on prioritized health issues. The three indicators rated as "not met" were related to research output targets, timely completion of researches, and the process of consistent technical review for selecting and approving research proposals that espouse the identified priority health issues.

Table 4. Median rating on the indicators for research capacity of centers for health development, November 2013 ( $\mathrm{n}=14$ )

\section{Area of research capacity \\ Research \\ 1. At least $50 \%$ of research outputs within the} management last 3 years are institutional collaborations.

2. At least $50 \%$ of researches in the last 3 years had been accomplished on time.

3. The technical review committee consistently selects and approves proposals that espouse the identified priority health issues.

\section{Partially met}

1. There is good evidence-based epidemiologic and socio-demographic description on priority health concerns.

2. Priority health concerns are made known to both the institution's research reviewers and researchers.

3. The research institution has an annual calendar of research activities which is closely followed and well attended.

4. Research proposals undergo committee review for technical soundness.

5. Researches have undergone extensive peer review in addition to that conducted by the committee.

6. There is/ are advisers that monitor progress of each research.

7. Funding for researches is allocated in the institutional budget.

8. Allocated research budget are properly utilized.

\section{Resource}

mobilization

1. There is a standardized procedure followed in the allocation of research grants to selected protocols.

2. Standardized procedure for research grants are observed and monitored.

3. Collaborative researches aligned with the research Health agenda are given budget priority.

4. The institution provides counterpart funding for collaborative researches.

5. The institution facilitates outsourcing of additional funds or tapping of other sources for a particular research study provided that this is adequately justified by the researchers.

\section{Structure/} Organization/ Monitoring/ Evaluation (SOME)
1. There is an officially recognized research unit that functions for research policy formulation, implementation, and monitoring.

2. There is a clear organizational structure with specific, well delineated, and documented CHD assignments and responsibilities for each position, including tenure of office.

3. There are clear-cut policies on conflicts of interest which covers all members of the research unit.

4. All information regarding organizational structure, objectives, policies, standard procedures, and other research-related matters are documented in a manual of operation.

5. The manual of operations for research is periodically updated and distributed to all members of the institution.

6. The research unit holds regular meetings attended by at least $90 \%$ of members.
1. Members of the research unit are appointed on a regular basis according to official institutional by-laws. 
Table 5. Capacity level of centers for health development, Philippines, November 2013

\begin{tabular}{ccc} 
Research Aspect & Mean score (\%) & Level/Category $^{b}$ \\
\hline Resource mobilization & 54.5 & Level 1 / FAIR \\
Research management & 43 & Level 0 / POOR \\
SOME $^{\mathrm{a}}$ & 30 & Level 0 / POOR \\
\hline
\end{tabular}

a SOME - structure, organization, monitoring and evaluation

${ }^{b}$ Capacity level: Level III - EXCELLENT (85-100\%), Level II - GOOD

(70-84\%), Level I - FAIR (51-69\%), Level 0 - POOR (<50\%) ${ }^{3}$

Resource mobilization. All the 5 indicators under resource mobilization were rated by the CHDs as "partially met" (Table 4). These included having a standardized procedure for allocating research grants and ensuring that the procedure was observed and monitored, budget priority given to collaborative researches that were aligned with the health research agenda, provision of counterpart funding for collaborative research, and facilitation in outsourcing additional funds.

Structure, organization, monitoring, and evaluation (SOME). One of the 7 SOME indicators was rated as "partially met" and all 6 others as "not met" (Table 4). None of the indicators was found to be "met satisfactorily".

\section{DISCUSSION}

The CHDs have fair capacity for resource mobilization and poor in the areas of research management and SOME. Research input was also lacking and research output was low.

These data suggest the need for CHDs to improve its capacity in all areas of institutional research, from input to process to output. It has been about 3 decades when the office of the Philippine President issued an executive order reorganizing the then Ministry of Health, with research as one of its functions - "Undertake health and medical research and conduct training in support of its priorities, programs, and activities"). ${ }^{4}$ However, the Philippines, like most developing countries, continues to experience problems related to research productivity, resources, and infrastructure..$^{5-9}$

Like other institutions in the health service sector, the CHD has the potential to produce high quality health research by virtue of the close working relationship of its health professionals with patients, both in clinical and community settings. ${ }^{10}$ However, there are obstacles to overcome for health service organizations to be successful in research - time, resources and infrastructure, skills and knowledge, and coordination..$^{10}$ Our findings are consistent with published obstacles for research, particularly those involving lack of resources and infrastructure. ${ }^{10-12} \mathrm{We}$ found that only two of the indicators of research capacity level were rated as "satisfactorily met" while the rest are either "partially met" (14 indicators) or "not met" (9 indicators). The areas that were rated as "not met" include presence of an officially recognized research unit that functions for research policy formulation, implementation, and monitoring; regular meeting of the unit; having a clear organizational structure; and existing research policies and manual of operations, among others. The absence of these basic research structures in the CHDs may indicate the possibility that research is not seen as an integral part of the institution.

The research situation is expected to improve with the recent efforts of the government to increase productivity in health research. First is the establishment of HSRM in 2012 by the DOH whose objectives are to generate more health researches to support the implementation of Universal Health Care and to increase capacity for research, knowledge production, use of researches for policy and programs, research management, and financing. Second is the passing of the 2013 law that formalizes the PNHRS and establishes the Philippine National Health Research Fund. ${ }^{1,5}$ These initiatives are expected to boost health and medical research in the country.

It was also found that all the CHDs are members of the Regional Health Research and Development Consortium (RHRDC), organized by DOST-PCHRD, in their respective regions, however, not all are actively involved in all the activities of the consortia. The regional director of the CHD sits as ex-oficio member of the research consortium, together with the respective regional directors of the Commission on Higher Education (CHED) and the Department of Science and Technology (DOST). As a member of the research consortium, the $\mathrm{CHD}$ is expected to participate in its regular activities. In this study, a CHD is considered as actively involved in the consortium if it participated in its regular activities. Our results show that only the setting of regional research agenda was actively participated in by $100 \%$ of the CHDs. It is noteworthy that the involvement of the CHDs in research methods training of the consortia was more of participation as trainees $(93 \%)$ rather than as resource persons (79\%). The provision of research expertise in short term research trainings organized by the consortia is one of the expected contributions of member-institutions of the research consortia. ${ }^{13}$ This implies that the CHDs are still in the process of developing its human capability given its current shortage of staff who are skilled in research, particularly in designing research proposals and in undertaking technical review of research proposals.

The low capacity level in the areas of research management and SOME as well as the low research productivity of the CHDs may indicate the possibility that research is not seen as an integral part of the job of the staff. Improving the research capacity of the CHDs by addressing the identified weaknesses that we found in this research will help ensure research productivity which will provide evidence to inform health policies and programs and consequently improve the health of Filipinos.

\section{CONCLUSION AND RECOMMENDATION}

This study found that the CHDs have fair capacity for resource mobilization and poor in the areas of research 
management and SOME. There is also lack of research input and low research output. Specific areas in research process were identified that need improvement: written policies related to research, research development program plan, institutional research agenda setting, and involvement in the activities of the Regional Health Research and Development Consortium (RHRDC), particularly in collaborative research, ethical review of research proposals, and establishment and maintenance of electronic research database.

Therefore, the following are the recommendations: 1) utilize the baseline data as inputs in the planning of a capacity building program and in deciding which areas need focus and priority; 2) use baseline data as information-base against which institutions will be able to monitor the progress and determine the effectiveness of its research capacity improvement activities; and 3) undertake research to assess individual research capability of staff including motivation to do research so that appropriate interventions can be applied.

\section{Acknowledgments}

This paper is part of the project that was financially supported by the DOH and PCHRD. We thank PCHRD for giving us permission to use the tool for measuring capacity level of research institutions in the areas of research management, resource mobilization, and SOME. We also thank Dr. Ma. Rosario Clarissa Vergeire and Dr. Alan Feranil for their inputs during the conceptualization of this project.

\section{Statement of Authorship}

All authors approved the final version submitted.

\section{Author Disclosure}

All authors declared no conflict of interest.

\section{Funding Source}

This study was funded by the DOH and PCHRD.

\section{REFERENCES}

1. Department of Health. Health Systems Research Management [Online]. 2017 [cited 2017 Feb]. Available from http://hsrm.doh. gov.ph.

2. Agulto M, Jamir J, Montoya J. Capability Building Program for the Center for Health Development Offices and Regional Hospitals [Memorandum of Agreement]. 2013.

3. Habacon R, Belizario V, Gonzaga G, Garcia L, Feranil A, Philippine Council for Health Research and Development-Institution Development Division Technical Advisory Group. Assessment tools of research capacity building for researchers, research institutions, and regional research consortia. 2013. pp 4-17.

4. Philippine Senate. Reorganizing the Ministry of Health, its attached agencies and for other purposes. Executive Order No. 119, series 1987. Official Gazette [Online]. 1987 [cited 2017 Feb]. Available from http://www.gov.ph/1987/01/30/executive-order-no-119-s-1987/.

5. Oxford Business Group. The Philippines: health research initiatives [Online]. 2013 [cited 2017 Jan]. Available from http://www. oxfordbusiness group.com/economic_updates/philippines-healthresearch-initiatives.

6. Abunto MA. The Philippine help desk [Online]. [cited 2017 Mar]. Available from www.pitt.edu/ super7/50011-51001/50601.ppt.

7. Council on Health Research for Development. Priorities for health research in the Philippines. Published on www.cohred.org Perspectives on Research for Health and on the PCHRD website www. pchrd.dost. gov.ph/

8. Pante F Jr. Health policy and research development in the Philippines. Journal of Philippine Development [Online]. 1990 [cited 2017 Feb]. Available from dirp3.pids.gov.ph/ris/pjd/pidsjpd90-1health.pdf.

9. Lansang MA, Dennis R. Building capacity in health research in the developing world. Bull World Health Organ. 2004; 82(10):764-70].

10. Pager S, Holden L, Golenko X. Motivators, enablers, and barriers to building allied health research capacity. J Multidiscip Healthc. 2012; 5:53-9.

11. Harrison RA. Barriers and opportunities to developing research capacity in primary care trusts: the views of staff attached to a primary care trust. Prim Health Care Res Dev [Abstract]. 2005; 6(3):185-9.

12. Morest VS, Jenkins D. Institutional research and the culture of evidence at community colleges. New York: Community College Research Center, Teachers College, Columbia University, 2007.

13. Philippine Council for Health Research and Development. Terms of reference for Regional Health Research and Development Consortium. 